\title{
An evaluation of anesthetic fade in motor evoked potential monitoring in spinal deformity surgeries
}

Ryo Ugawa ${ }^{1}$, Tomoyuki Takigawa ${ }^{1 *}$, Hiroko Shimomiya ${ }^{2}$, Takuma Ohnishi ${ }^{2}$, Yuri Kurokawa ${ }^{2}$, Yoshiaki Oda ${ }^{1}$, Yasuyuki Shiozaki ${ }^{1}$, Haruo Misawa', Masato Tanaka ${ }^{3}$ and Toshifumi Ozaki ${ }^{1}$

\begin{abstract}
Background: Intraoperative neuromonitoring using motor evoked potentials (MEP) satisfactorily detects motor tract integrity changes during spinal surgery. However, monitoring is affected by "anesthetic fade," in which the stimulation threshold increases because the waveform amplitude decreases with the accumulation of propofol. Therefore, the purpose of this study was to clarify the effect of anesthetic fade on transcranial MEPs by investigating the time-dependent changes of amplitude during spinal deformity surgeries.

Methods: We retrospectively reviewed medical records of 142 spinal deformity patients (66 patients with idiopathic scoliosis, 28 with adult spinal deformities, 19 with neuromuscular scoliosis, 17 with syndromic scoliosis, and 12 with congenital scoliosis). The average age was 28 years (range, 5 to 81 years). MEPs were recorded bilaterally from the abductor digiti minimi (ADM) and abductor hallucis (AH) muscles during spinal deformity surgeries. The Wilcoxon signed-rank test was used to investigate the time-dependent changes of amplitude after propofol infusion to evaluate anesthetic fade effects.

Results: The average time to baseline from initial propofol infusion was $113 \mathrm{~min}$ (range, 45 to $182 \mathrm{~min}$ ). In the ADM, the amplitude was $52 \%$ at $1 \mathrm{~h}$ after initial propofol infusion, $102 \%$ at $2 \mathrm{~h}, 105 \%$ at $3 \mathrm{~h}, 101 \%$ at $4 \mathrm{~h}, 86 \%$ at $5 \mathrm{~h}$, and $81 \%$ at $6 \mathrm{~h}$. Compared to the $2-\mathrm{h}$ time point, MEP decreased significantly by $16 \%$ at $5 \mathrm{~h}(P<0.0005)$ and by $21 \%$ at $6 \mathrm{~h}(P<0.05)$. In the $\mathrm{AH}$, the amplitude was $49 \%$ at $1 \mathrm{~h}$ after initial infusion of propofol, $102 \%$ at $2 \mathrm{~h}, 102 \%$ at $3 \mathrm{~h}, 92 \%$ at $4 \mathrm{~h}, 71 \%$ at $5 \mathrm{~h}$, and $63 \%$ at $6 \mathrm{~h}$. Compared to the 2 -h time point, MEP decreased significantly by $10 \%$ at $4 \mathrm{~h}(P<0.005)$, by $31 \%$ at $5 \mathrm{~h}(P<0.0000005)$, and by $39 \%$ at $6 \mathrm{~h}(P<0.05)$.

Conclusions: MEP amplitude significantly decreased in the upper limbs at 5 and $6 \mathrm{~h}$ and in the lower limbs at 4, 5, and $6 \mathrm{~h}$ after the initial infusion of propofol, respectively. The influence of anesthetic fade could influence false positive MEPs during long spinal surgeries.
\end{abstract}

Keywords: Intraoperative neuromonitoring, Motor evoked potential, Spinal deformity surgery, Alarm point, Propofol, False positive, Anesthetic fade, Abductor digiti minimi, Abductor hallucis, Amplitude

\footnotetext{
* Correspondence: takigawa2004@yahoo.co.jp

'Department of Orthopedic Surgery, Okayama University Hospital, 2-5-1

Shikata-cho, Okayama City, Okayama 700-8558, Japan

Full list of author information is available at the end of the article
}

(c) The Author(s). 2018 Open Access This article is distributed under the terms of the Creative Commons Attribution 4.0 International License (http://creativecommons.org/licenses/by/4.0/), which permits unrestricted use, distribution, and reproduction in any medium, provided you give appropriate credit to the original author(s) and the source, provide a link to the Creative Commons license, and indicate if changes were made. The Creative Commons Public Domain Dedication waiver (http://creativecommons.org/publicdomain/zero/1.0/) applies to the data made available in this article, unless otherwise stated. 


\section{Background}

Iatrogenic spinal cord injury is the most serious complication in scoliosis surgery $[1,2]$. The potential for intraoperative neurologic complications has become a particular concern in recent years because patients with many types of deformities are undergoing surgical treatment. As a result, intraoperative neuromonitoring is gaining popularity; therefore, development and thorough understanding of it are necessary to reduce the risk of intraoperative neurologic complications. Transcranial motor evoked potentials (MEP), a type of intraoperative neuromonitoring, has excellent sensitivity for detecting changes in motor tract integrity during spinal surgery [3].

The MEP amplitude can decrease even in the absence of any nerve damage (false positive), and this may be caused by electrode failure, intraoperative hypotension, or hypothermia [4, 5]. In addition, most anesthetics, other than remifentanil and ketamine, can cause false positive results by inhibiting MEP in a dose-dependent fashion [6]. Total intravenous anesthesia using propofol infusion is preferred when MEP monitoring is performed during surgery [7, 8]. However, MEP responses have been observed to deteriorate over the duration of surgery under general anesthesia. MacDonald et al. described "fading MEP" with prolonged exposure to anesthesia [9]. Lyon et al. reported that muscle MEPs tend to exhibit gradually rising thresholds throughout surgery despite stable anesthesia [10].

Spinal deformity surgery usually requires a long operation, so patients are susceptible to anesthetic fade. In addition, corrective forces that have a potential risk of spinal cord damage are usually applied at the final stages of spinal deformity surgery. Therefore, when a decrease in MEP occurs, spine surgeons need to determine whether it is caused by the surgical procedure or anesthetic fade. To our knowledge, the magnitude of amplitude decrease over time due to anesthetic fade has not been quantified in spinal surgery. We retrospectively reviewed a series of patients who underwent spinal deformity surgeries using transcranial MEP monitoring. We measured changes in amplitude over time under stable anesthetic conditions.

\section{Methods}

Following approval from our ethics committee, we reviewed the records of 159 patients who had undergone surgical correction of spinal deformities at our institution from 2013 to 2016. We restricted our study to patients who received maintenance of anesthesia with total intravenous anesthesia during the period of MEP monitoring. We excluded eight cases in which an adequate waveform could not be obtained during the surgery because of preoperative neurological deficits and nine cases in which new neurologic deficits were found after the surgery (i.e., true positive cases) (Table 1). Using these criteria, we included 142
Table 1 Inclusion and exclusion criteria

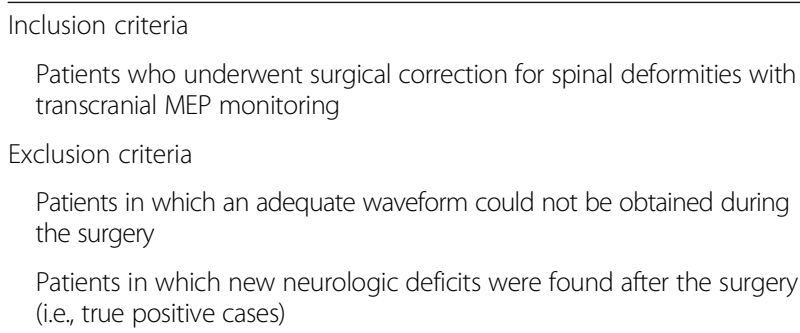

patients who underwent surgical correction for spinal deformities with transcranial MEP monitoring (Table 2).

The operative reports, anesthesia records, and spinal cord monitoring records were analyzed to determine relationships between duration of anesthesia and consequent loss in amplitude of the MEP and to ascertain the effect of intravenous propofol.

Serial neurophysiological monitoring of spinal cord motor tract function was performed by repeatedly recording both lower and upper extremity efferent transcranial electric motor potentials from the beginning of anesthesia to the end of anesthesia. MEP monitoring was the principal component of a broader neuromonitoring protocol, which included train-of-four (TOF) peripheral nerve stimulation to test for clearance of muscle relaxants from the neuromuscular junction. All neuromonitoring for this study was performed by one experienced neurophysiological monitoring group using a common, algorithmically based standard for both consistency and improved detection accuracy.

\section{Technique for motor evoked potential monitoring}

All patients underwent the standard monitoring techniques for spine surgery at our institution. MEPs were typically recorded from the deltoid, abductor digiti minimi (ADM) of each upper extremity, quadriceps, tibialis anterior, and abductor hallucis $(\mathrm{AH})$ of each lower extremity using surface-patch electrodes (disposable electrode Vitrode V; Nihon Kohden, Japan). In this study, we utilized amplitudes of MEP from the ADM and AH. MEP recordings typically include these muscles, which are known to have strong pyramidal innervation [11].

These myogenic responses were elicited with the use of a commercially available transcranial electrical stimulator (Stimulator SEN-4100; Nihon Kohden, Japan) that delivered

Table 2 Types of spinal deformity

\begin{tabular}{lc}
\hline Spinal deformity (142 patients) & \\
\hline Idiopathic scoliosis & 66 \\
Adult deformity & 28 \\
Neuromuscular scoliosis & 19 \\
Syndromic scoliosis & 17 \\
Congenital scoliosis & 12 \\
\hline
\end{tabular}


an anodal pulse train between two corkscrew electrodes (Coil Electrode SN-100-1500 AD; UNIQUE MEDICAL, Japan) inserted subcutaneously over the motor cortex regions C3-C4 (International 10/20 System). Table 3 shows the MEP measurement parameters.

\section{Anesthetic management}

All patients' anesthesia was maintained with total intravenous anesthesia during the period of MEP monitoring, as shown in Fig. 1. In 44 pediatric patients, only an initial small amount of inhalation anesthetic (sevoflurane, $0.8 \%$ to $8.0 \%$ ) was used when securing venous access. A muscle relaxant (rocuronium bromide, 15 to $50 \mathrm{mg}$ ) was administered before intubation. Following induction and intubation, all inhalational agents were discontinued and no additional muscle relaxants were administered during surgery. An arterial line was placed to monitor blood pressure. Thereafter, general anesthesia was maintained with propofol using target-controlled infusion (TCI; 1.5 to $5 \mu \mathrm{g} / \mathrm{ml}$ ) and remifentanil ( 0.1 to $0.5 \mu \mathrm{g} / \mathrm{kg} / \mathrm{min})$ with particular efforts made to achieve a stable, target range (30 to 45) of the bispectral index (BIS; BIS ${ }^{\mathrm{ma}}$ LoC 2 Channel OEM Module; Medtronic, USA) and a mean arterial blood pressure of at least $65 \mathrm{mmHg}$. The ventilator was set to maintain normocapnia, and the target $\mathrm{SpO} 2$ was over $96 \%$. No muscle relaxant was used after intubation so as not to compromise the transcranial electric MEP amplitudes. Monitoring of the neuromuscular junction with TOF stimulation of the posterior tibial nerve and recording compound muscle action potentials from the $\mathrm{AH}$ muscle ensured adequate clearance of the neuromuscular blockade. When the TOF was low and the control waveform could not be obtained, reversal of the neuromuscular blockade was performed using sugammadex [12].

\section{Electrophysiology data analysis}

We reviewed the MEP records and investigated the time when the baseline was obtained (the course from the initial infusion of propofol). We set the amplitude of MEP as $100 \%$ baseline when the influence of neuromuscular blockade sufficiently disappeared before application of spinal instruments. Recovery from neuromuscular blockade was identified by a TOF $>90 \%$ [13]. Then, we reviewed the time-dependent changes of amplitude at $1 \mathrm{~h}$, $2 \mathrm{~h}, 3 \mathrm{~h}, 4 \mathrm{~h}, 5 \mathrm{~h}$, and $6 \mathrm{~h}$ after the initial infusion of propofol. About ADM, amplitudes were obtained from 120 cases at $1 \mathrm{~h}, 127$ cases at $2 \mathrm{~h}, 127$ cases at $3 \mathrm{~h}, 111$ cases at $4 \mathrm{~h}, 75$ cases at $5 \mathrm{~h}$, and 18 cases at $6 \mathrm{~h}$. About AH, amplitudes were obtained from 129 cases at $1 \mathrm{~h}, 139$ cases at $2 \mathrm{~h}, 139$ cases at $3 \mathrm{~h}, 122$ cases at $4 \mathrm{~h}, 86$ cases at $5 \mathrm{~h}$, and 21 cases at $6 \mathrm{~h}$. The waveform closest to each time was chosen. Amplitudes of the left and right sides were averaged in ADM and $\mathrm{AH}$, respectively.

We reviewed the time from the initial infusion of propofol to the start of surgery. We investigated the period during which surgery was possible with a stable waveform.

\section{Statistical analysis}

The Wilcoxon signed-rank test was used to compare the changes over time. All $P$ values were two-sided, and $P$ values of 0.05 or less were considered statistically significant. All statistical analyses were performed with EZR (Kanda, 2012; Saitama Medical Centre, Jichi Medical University, http://www.jichi.ac.jp/saitama-sct/SaitamaHP. files/statmedEN.html), which is a graphical user interface for R (version 2.13.0; The R Foundation for Statistical Computing, Vienna, Austria). More precisely, it is a modified version of $\mathrm{R}$ commander (version 1.6-3) that was designed to add statistical functions frequently used in biostatistics.

\section{Results}

There were 111 (78\%) female patients and 31 (22\%) male patients ranging in age from 5 to 81 years (average, 28 years) at the time of surgery. The average operating time was $282.1 \mathrm{~min}$ (range, 162 to $480 \mathrm{~min}$ ). One hundred eighteen cases were dorsal operations, 22 cases were ventral operations, and 2 cases were combined ventral and dorsal operations. The average number of levels fused was 9.2 segments (range, 2 to 17 segments). There were no complications related to MEP monitoring. As perioperative comorbidities, surgical site infection (SSI) was identified in 5 cases, postoperative deep

Table 3 Modalities and standardized institutional settings for the assessment of MEP

\begin{tabular}{lll}
\hline & MEP stimulation & MEP recording \\
\hline Monitoring system & Neuromaster MEE-1216 (Nihon Kohden, Japan) & \\
Montage of electrodes & Corkscrew electrodes (UNIQUE MEDICAL, Japan) & Surface-patch electrodes (Nihon Kohden, Japan) \\
C3-C4 (according to the international 10/20 system) & Bilateral abductor digiti minimi muscles \\
Specifications & Stimulus (anode), repeated train of 5-7 stimuli & Filters, 0.05-1.5 kHz \\
& Interstimulus interval, 2 ms & Average, 5 \\
& Intensity, 150-200 mA & \\
& Duration, 0.5 ms, biphasic & \\
\hline
\end{tabular}




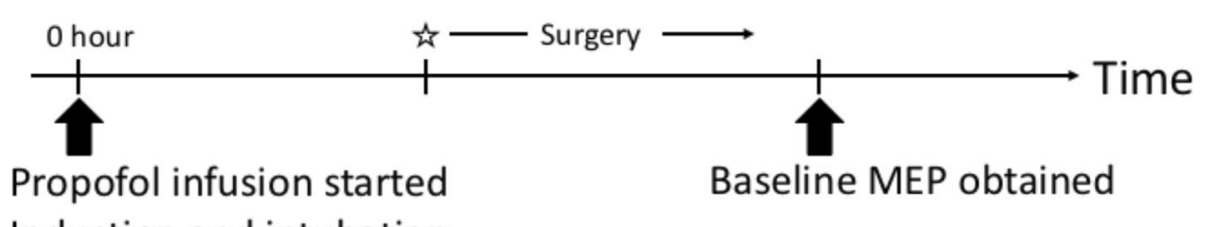

Induction and intubation

Rocuronium bromide, $15-50 \mathrm{mg}$

Sevoflurane, $0.8-8.0 \%$ (44 pediatric cases)

Propofol infusion: 1.5-5.0 $\mathrm{\mu g} / \mathrm{ml}$ (TCl); Target BIS: 30-45

Remifentanil infusion rate: $0.1-0.5 \mathrm{ug} / \mathrm{kg} / \mathrm{min}$

Fig. 1 Schema of the time course. Time 0 was defined as when the infusion of propofol started. Muscle relaxant was administered only upon propofol induction. A small amount of inhalation anesthetic (sevoflurane, 0.8 to 8.0\%) was used for anesthetic induction in 44 pediatric cases. Anesthesia was maintained with continuous infusion of propofol and remifentanil. Star marker, start of surgery; MEP, motor evoked potential; TCl, target-controlled infusion (a device to deliver the drug to achieve specific predicted target drug concentrations in the blood); BIS, bispectral index (a device to assess the depth of anesthesia)

vein thrombosis (DVT) in 3 cases, urinary tract infection in 1 case, postoperative delirium in 1 case, and rising hepatic enzyme of unknown cause in 1 case. We performed debridement reoperation for 4 SSI cases. The average time to obtain the baseline from the initial infusion of propofol was $113 \mathrm{~min}$ (range, 45 to $182 \mathrm{~min}$ ). In the upper limbs (ADM), the amplitude was $52 \%$ at $1 \mathrm{~h}$ after the initial infusion of propofol, $102 \%$ at $2 \mathrm{~h}, 105 \%$ at $3 \mathrm{~h}, 101 \%$ at $4 \mathrm{~h}$, $86 \%$ at $5 \mathrm{~h}$, and $81 \%$ at $6 \mathrm{~h}$. Compared to the 2-h time point (approximation of the time of $113 \mathrm{~min}$ we got, the baseline we mentioned earlier), the amplitude at $5 \mathrm{~h}$ significantly decreased by $16 \%(P<0.0005)$ and that at $6 \mathrm{~h}$ significantly decreased by $21 \%(P<0.05)$ (Fig. $2 a)$. In the lower limbs (AH), the amplitude was $49 \%$ at $1 \mathrm{~h}$ after the initial infusion of propofol, $102 \%$ at $2 \mathrm{~h}, 102 \%$ at $3 \mathrm{~h}, 92 \%$ at $4 \mathrm{~h}, 71 \%$ at $5 \mathrm{~h}$, and $63 \%$ at $6 \mathrm{~h}$. Compared to the 2 -h time point, the amplitude at $4 \mathrm{~h}$ significantly decreased by $10 \%(P<0.005)$, that at $5 \mathrm{~h}$ significantly decreased by $31 \%$ $(P<0.0000005)$, and that at $6 \mathrm{~h}$ significantly decreased by 39\% $(P<0.05)$ (Fig. 2b).

The average time from the initial infusion of propofol to the start of surgery was $55 \mathrm{~min}$ (range, 0 to $89 \mathrm{~min}$ ). The waveform decreasing started to occur in $4 \mathrm{~h}$ from the start of propofol, and it took about $1 \mathrm{~h}$ to start the surgery. Considering those things, MEP varied at $3 \mathrm{~h}$ after the start of the surgery.

\section{Discussion}

We reviewed the records of patients who had undergone surgical correction of spinal deformities. We allowed $113 \mathrm{~min}$ from the initial infusion of propofol to obtain a sufficient baseline. This seemed to be affected by deep anesthesia during intubation (inhalation anesthetic, propofol, and neuromuscular blockade).
At $4 \mathrm{~h}$ after the initial infusion of propofol, the amplitude of MEP decreased by $10 \%$ in the lower limbs. At $5 \mathrm{~h}$ after the initial infusion of propofol, the amplitude of MEP decreased by $16 \%$ in the upper limbs and $31 \%$ in the lower limbs. In our cases, the time from the initial infusion of propofol to the start of the surgery averaged $55 \mathrm{~min}$, and then the waveform was stable for only about $2 \mathrm{~h}$ (from $1 \mathrm{~h}$ to $3 \mathrm{~h}$ after the start of surgery). As mentioned previously, spinal deformity surgery usually requires a long operation time. Lonner et al. reported that the operating time for the treatment of adolescent idiopathic scoliosis was $180.2 \mathrm{~min}$ for experienced surgeons and $221.9 \mathrm{~min}$ for inexperienced surgeons [14]. Taking this into consideration, there is a possibility that a sufficient waveform is not maintained by the end of the surgery. In this study, the average operating time was $282.1 \mathrm{~min}$, because our study includes syndromic scoliosis and advanced deformities that require osteotomy. Such cases may require a longer operation time, and the effect of anesthetic fade may increase.

Anecdotal reports suggest that MEP responses degrade or undergo anesthetic fade during surgery despite unchanged anesthetic levels and other physiologic variables [10]. MEP tends to exhibit gradually rising thresholds during the hours of surgery. Sedative-hypnotics (e.g., propofol) cause unconsciousness by producing corticocortical inhibition, possibly by GABA-mediated inhibitory interneuron activity within the cerebral cortex [15] with minimal depression of spinal alpha motor neurons [16]. Propofol, like halogenated agents, produces a dose-dependent depression of MEP responses [17, 18]. The influence of propofol is also suggested in this study.

In this study, the lower limbs were more affected by anesthetic fade than the upper limbs. This phenomenon has been reported previously [9]. A study about MEP 


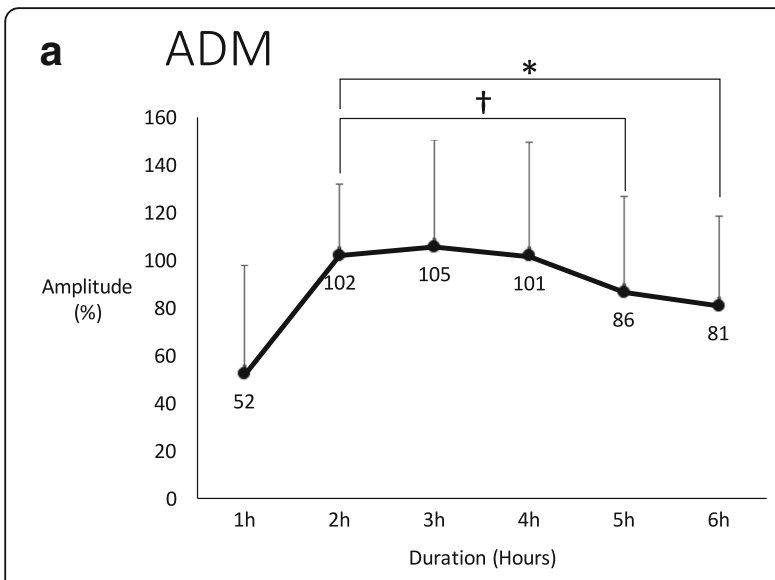

\section{b $\quad \mathrm{AH}$}

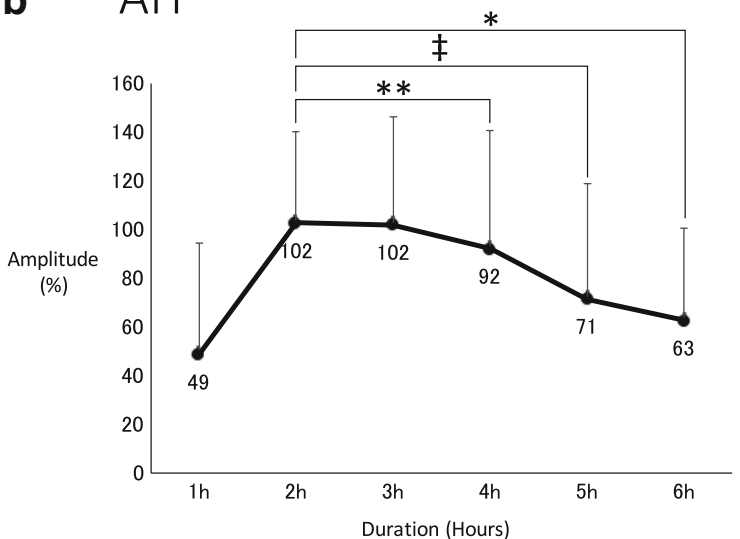

Fig. 2 Amplitude changes of the abductor digiti minimi (ADM) and abductor hallucis $(\mathrm{AH})$ muscles post-propofol infusion. a In the ADM, the amplitude at 5 and $6 \mathrm{~h}$ was significantly lower than that at $2 \mathrm{~h}$. Amplitudes were obtained from 120 cases at $1 \mathrm{~h}, 127$ cases at $2 \mathrm{~h}$, 127 cases at $3 h, 111$ cases at $4 h, 75$ cases at 5 h, and 18 cases at $6 \mathrm{~h}$. $\mathbf{b}$ In the $\mathrm{AH}$, the amplitude at 4, 5, and $6 \mathrm{~h}$ was significantly lower than at $2 \mathrm{~h}$. Amplitudes were obtained from 129 cases at $1 \mathrm{~h}$, 139 cases at 2 h, 139 cases at 3 h, 122 cases at 4 h, 86 cases at 5 h, and 21 cases at 6 h. $\left({ }^{*} P<0.05,{ }^{*} P<0.005,{ }^{\dagger} P<0.0005,{ }^{\ddagger} P<0.0000005\right)$. Values are expressed as means, and bars represent standard deviations

under sevoflurane anesthesia reported that high-frequency stimulation restored MEP to the baseline level in the upper extremities but not in the lower extremities [19]. The authors stated that it remained unclear what mechanism was responsible for the discrepancy in MEP responses between the upper and lower limbs. This discrepancy may have resulted from differences in the corticospinal drive mechanism between the upper and lower limbs; for example, D-wave refractory periods. In MEP under propofol anesthesia, the fade phenomenon may occur with a similar mechanism. Additional basic research is required to answer this question.

With respect to the alarm point of MEP, according to retrospective studies, Pelosi et al. reported a 50\% decrease in amplitude [3], and Langeloo et al. reported an
80\% decrease in amplitude [20]. According to a prospective multicenter study from the Spinal Cord Monitoring Working Group of the Japanese Society for Spine Surgery and Related Research, they recommend designating a 70\% decrease in amplitude as the alarm point for routine spinal cord monitoring, particularly during surgery for spinal deformities, ossification of the posterior longitudinal ligament, and extramedullary spinal cord tumors [21]. The problem with this alarm point is that anesthetic fade is not considered. Other causes of false positives include intraoperative hypothermia and hypotension $[4,5]$. In our study, there were no cases of persistent intraoperative hypothermia or hypotension, and the amplitude of the lower limb significantly decreased at $4 \mathrm{~h}$ and markedly decreased at $5 \mathrm{~h}$ after the initial infusion of propofol. The influence of anesthetic fade could potentially lead to false positive MEPs during long spinal surgeries.

The limitation of this study is that it was a retrospective study, and it included patients with many types of spinal deformities. Spinal cord monitoring in neuromuscular scoliosis is possible but potentially unreliable [22]. The inclusion of patients with neuromuscular scoliosis and patients with mild preoperative paralysis may have influenced our results. We included all cases in which no new postoperative neurological deficits were observed; therefore, we might have included cases with some damage to the spinal cord where no neurological deficits were identified. As another limitation, TCI was used for administration of propofol, and the total amount of propofol administered was unknown. If we know the total amount of propofol administered, it would be possible to take into consideration the amount until the fade phenomenon occurred.

\section{Conclusions}

In summary, the amplitude of MEP significantly decreased in the lower limbs at $4 \mathrm{~h}$ and in the upper and lower limbs at $5 \mathrm{~h}$ after the initial infusion of propofol. These results may be helpful to reduce the incidence of false positives in MEP monitoring since the influence of anesthetic fade on MEP is inevitable during a long spinal surgery.

\section{Abbreviations}

ADM: Abductor digiti minimi; AH: Abductor hallucis; MEP: Motor evoked potential; TCl: Target-controlled infusion; TOF: Train-of-four

\section{Availability of data and materials}

The datasets used and analyzed during the current study are available from the corresponding author on reasonable request.

\section{Authors' contributions}

$\mathrm{RU}$ and $T T$ designed the study. RU, TT, YS, HM, MT, and TOz selected the appropriate patients and included them in this study. RU, HS, TOh, and YK reviewed the amplitude records of MEP. YO, YS, and HM performed the statistical analysis and interpreted the results. RU drafted the manuscript. All of the authors critically revised the manuscript. The final manuscript was approved by all authors. 


\section{Ethics approval and consent to participate}

The present study was approved by the Okayama University Graduate School of Medicine, Dentistry, and Pharmaceutical Sciences and Okayama University Hospital (Ethics Committee No. 1707-003). The requirement for informed consent was waived due to this study's retrospective design.

\section{Consent for publication}

Not applicable

\section{Competing interests}

The authors declare that they have no competing interests.

\section{Publisher's Note}

Springer Nature remains neutral with regard to jurisdictional claims in published maps and institutional affiliations.

\section{Author details}

${ }^{1}$ Department of Orthopedic Surgery, Okayama University Hospital, 2-5-1 Shikata-cho, Okayama City, Okayama 700-8558, Japan. ${ }^{2}$ Division of Medical Support, Okayama University Hospital, 2-5-1 Shikata-cho, Okayama City, Okayama 700-8558, Japan. ${ }^{3}$ Department of Orthopedic Surgery, Okayama Rosai Hospital, 1-10-25 Chikko-Midorimachi, Okayama City, Okayama 702-8055, Japan.

Received: 18 July 2018 Accepted: 30 August 2018

Published online: 05 September 2018

\section{References}

1. Bridwell KH, Lenke LG, Baldus C, Blanke K. Major intraoperative neurologic deficits in pediatric and adult spinal deformity patients. Incidence and etiology at one institution. Spine. 1998;23:324-31.

2. Schwartz DM, Auerbach JD, Dormans JP, Flynn J, Drummond DS, Bowe JA et al. Neurophysiological detection of impending spinal cord injury during scoliosis surgery. J Bone Joint Surg Am. 2007;89:2440-9.

3. Pelosi L, Lamb J, Grevitt M, Mehdian SM, Webb JK, Blumhardt LD. Combined monitoring of motor and somatosensory evoked potentials in orthopaedic spinal surgery. Clin Neurophysiol. 2002;113:1082-91.

4. Leslie K, Sessler DI, Bjorksten AR, Moayeri A. Mild hypothermia alters propofol pharmacokinetics and increases the duration of action of atracurium. Anesth Analg. 1995;80:1007-14.

5. Othman Z, Lenke LG, Bolon SM, Padberg A. Hypotension-induced loss of intraoperative monitoring data during surgical correction of scheuermann kyphosis: a case report. Spine (Phila Pa 1976). 2004;29:E258-65.

6. Kawaguchi M, Furuya H. Intraoperative spinal cord monitoring of motor function with myogenic motor evoked potentials: a consideration in anesthesia. J Anesth. 2004;18:18-28.

7. Scheufler KM, Reinacher PC, Blumrich W, Zentner J, Priebe HJ. The modifying effects of stimulation pattern and propofol plasma concentration on motor-evoked potentials. Anesth Analg. 2005;100:440-7.

8. Hayashi H, Kawaguchi M, Yamamoto Y, Inoue S, Koizumi M, Ueda Y, et al. Evaluation of reliability of post-tetanic motor-evoked potential monitoring during spinal surgery under general anesthesia. Spine (Phila Pa 1976). 2008; 33:E994-1000

9. Macdonald DB. Intraoperative motor evoked potential monitoring: overview and update. J Clin Monit Comput. 2006:20:347-77.

10. Lyon R, Feiner J, Lieberman JA. Progressive suppression of motor evoked potentials during general anesthesia: the phenomenon of "anesthetic fade". J Neurosurg Anesthesiol. 2005:17:13-9.

11. Kothbauer KF. Intraoperative neurophysiologic monitoring for intramedullary spinal-cord tumor surgery. Neurophysiol Clin. 2007;37:407-14.

12. Pongrácz A, Szatmári S, Nemes R, Fülesdi B, Tassonyi E. Reversal of neuromuscular blockade with sugammadex at the reappearance of four twitches to train-of-four stimulation. Anesthesiology. 2013;119:36-42.

13. Eriksson LI, Sundman E, Olsson R, Nilsson L, Witt H, Ekberg O, et al. Functional assessment of the pharynx at rest and during swallowing in partially paralyzed humans: simultaneous videomanometry and mechanomyography of awake human volunteers. Anesthesiology. 1997;87:1035-43.

14. Lonner BS, Auerbach JD, Estreicher MB, Kean KE. Thoracic pedicle screw instrumentation: the learning curve and evolution in technique in the treatment of adolescent idiopathic scoliosis. Spine. 2009;34:2158-64.
15. Antkowiak B. Different actions of general anesthetics on the firing patterns of neocortical neurons mediated by the GABA(A) receptor. Anesthesiology. 1999;91:500-11.

16. Kakinohana M, Fuchigami T, Nakamura S, Kawabata T, Sugahara K Propofol reduces spinal motor neuron excitability in humans. Anesth Analg. 2002;94:1586-8.

17. Inoue S, Kawaguchi M, Takashi S, Kakimoto M, Sakamoto T, Kitaguchi K, et al. Intraoperative monitoring of myogenic motor-evoked potentials from the external anal sphincter muscle to transcranial electrical stimulation. Spine (Phila Pa 1976). 2002;27:E454-9.

18. Nathan N, Tabaraud F, Lacroix F, Mouliès D, Viviand X, Lansade A, et al. Influence of propofol concentrations on multipulse transcranial motor evoked potentials. Br J Anaesth. 2003;91:493-7.

19. Shida Y, Shida C, Hiratsuka N, Kaji K, Ogata J. High-frequency stimulation restored motor-evoked potentials to the baseline level in the upper extremities but not in the lower extremities under sevoflurane anesthesia in spine surgery. J Neurosurg Anesthesiol. 2012;24:113-20.

20. Langeloo DD, Lelivelt A, Louis Journée $H$, Slappendel $R$, de Kleuver M. Transcranial electrical motor-evoked potential monitoring during surgery for spinal deformity: a study of 145 patients. Spine (Phila Pa 1976). 2003;28:1043-50.

21. Kobayashi S, Matsuyama Y, Shinomiya K, Kawabata S, Ando M, Kanchiku T, et al. A new alarm point of transcranial electrical stimulation motor evoked potentials for intraoperative spinal cord monitoring: a prospective multicenter study from the Spinal Cord Monitoring Working Group of the Japanese Society for Spine Surgery and Related Research. J Neurosurg Spine. 2014:20:102-7.

22. Hammett TC, Boreham B, Quraishi NA, Mehdian SM. Intraoperative spinal cord monitoring during the surgical correction of scoliosis due to cerebral palsy and other neuromuscular disorders. Eur Spine J. 2013;22:S38-41.
Ready to submit your research? Choose BMC and benefit from:

- fast, convenient online submission

- thorough peer review by experienced researchers in your field

- rapid publication on acceptance

- support for research data, including large and complex data types

- gold Open Access which fosters wider collaboration and increased citations

- maximum visibility for your research: over $100 \mathrm{M}$ website views per year

At $\mathrm{BMC}$, research is always in progress.

Learn more biomedcentral.com/submissions 